OPEN ACCESS

Edited by:

Daniel Balsalobre-Lorente, University of Castilla-La Mancha,

Spain

Reviewed by:

Luigi Aldieri,

University of Salerno, Italy

Ehsan Elahi,

Shandong University of Technology,

China

*Correspondence:

Ye Chenyun

ycy7290@163.com

Specialty section:

This article was submitted to Environmental Economics and Management,

a section of the journal

Frontiers in Environmental Science

Received: 13 September 2021

Accepted: 28 October 2021

Published: 01 December 2021

Citation:

Avotra AARN, Chenyun Y, Yongmin W,

Lijuan $Z$ and Nawaz A (2021)

Conceptualizing the State of the Art of Corporate Social Responsibility (CSR) in Green Construction and Its Nexus to

Sustainable Development.

Front. Environ. Sci. 9:774822.

doi: $10.3389 /$ fenvs.2021.774822

\section{Conceptualizing the State of the Art of Corporate Social Responsibility (CSR) in Green Construction and Its Nexus to Sustainable Development}

\author{
Andrianarivo Andriandafiarisoa Ralison Ny Avotra ${ }^{1}$, Ye Chenyun ${ }^{2 *}$, Wu Yongmin ${ }^{3}$, \\ Zhang Lijuan ${ }^{3}$ and Ahsan Nawaz ${ }^{4}$
}

${ }^{1}$ Business School, Zhejiang Wanli University, Ningbo, China, ${ }^{2}$ School of Accounting, Shandong Management University, Jinan, China, ${ }^{3}$ Business School, University of International Business and Economics, Beijing, China, ${ }^{4}$ College of Civil Engineering and Architecture, Zhejiang University, Hangzhou, China

The study has been investigated on conceptualizing the state of the art of cooperate social responsibility (CSR) in green construction and its nexus to sustainable development. The research objective is to find out the significant relationship between CSR and green construction and further link green construction with sustainable development. The data has been collected from the 319 respondents working on different projects in the construction industry of China. The study is quantitative by nature. SEM analysis with the help of Smart-PLS has been applied to test the hypothesis relationship and mediations between components of CSR, green construction, and sustainable development. Results define that green procurement as a component of green construction strongly mediates between corporate social responsibility and sustainable development, and green design and $\mathrm{CO}_{2}$ emission moderately mediates between corporate social responsibility and sustainable development. This research would add values, benefits, and knowledge toward reducing environmental temperature with the help of green construction occupying the effects of CSR on it. It would be helpful to change the trends in the construction industry to make environmental health protective and to boost the sustainable development.

Keywords: corporate social responsibility (CSR), green construction, sustainable development, green procurement, CO2 emission

\section{INTRODUCTION}

In recent decades, several academics in management have drawn attention to cooperate social responsibility (CSR) as a concept. The majority have developed distinct CSR idea models and theories, which lead to varied methods for CSR. To develop a common form of implementation of the CSR approach that reflects the interest of shareholders and the community, it is sufficient to summarize the commonalities and differences between CSR theories. The participant theory has been well-known since the 1990s as a direct alternative and challenge to the concept of shareholder value. It claims that since the 1960s, the number of stakeholders has grown extensively, and the effect on companies should not be ignored.

Stakeholder perceptions of CSR are influenced by how businesses respond to a stakeholder group's overall social concerns. Since it boosts intangible corporate resources such as brand equity 
and reputation, the concept is quickly gaining traction in academic and business literature. Researchers and practitioners have become increasingly interested in how customers perceive CSR since it is believed to enhance customer-related advantages such as satisfaction, repurchase intentions, and willingness to recommend the company to others.

Construction methods that limit negative consequences on individuals and society are green architecture or green design. The green architect or designer attempts to safeguard the air, water, soil materials, and building processes by utilizing ecologically friendly construction materials. Green building design begins with an in-depth knowledge of the site beauty and complexity. Some aspects may be used by designers to recreate certain ecosystems. Buildings in urban areas must be redesigned to accommodate new types of living spaces.

The term sustainable has become a crucial perspective in managing firms through a comprehensive approach that considers companies' economic, environmental, and social elements. As the importance of sustainable development has grown, sustainable business ideas have evolved over the last 6 decades. Since the Brundtland Report was published in 1987, the concept of sustainable development has played a significant role in policymaking. For this reason, the sustainability of corporations has become a prominent study issue. It would not be easy to accomplish sustainable development without the help of companies. Theories investigate why and how acts, events, and ideas occur as a cohesive description or explanation of occurrences (Iqbal et al., 2014; Zhou et al., 2021). As a result, theories play an important role in human research, assisting in the understanding, characterization, explanation, and prediction of events. Sustainability was first considered in business management in the 1930s, even before the Brundtland report was published. Since then, companies sustainable-related thinking has changed, and various theories investigating the multidimensional links between sustainable and firms have been suggested and begin to evolve. Corporate social responsibility (CSR), stakeholder theory (ST), and corporate sustainable (CS) are examples of these theories. This indicates significant efforts as well as research possibilities in this sector.

Various studies have investigated the environmental quality and agricultural sustainability considering issues of resource utilization, public policies, and extreme weather events (Elahi et al., 2018; Elahi et al., 2019; Elahi et al., 2021). Similarly, some studies have focused on green ecology, green technology, regional environmental efficiency, environmental regulations, and environmental strategies (Peng et al., 2018; Tu et al., 2019). However, until now, limited research work has been found on green construction and its impacts on sustainable development and environmental quality. Therefore, the current study estimates the significant relationship between CSR and green construction and further to link green construction with sustainable development and environmental management.

\section{Research Hypothesis}

Research on CSR is becoming increasingly popular. Being a socially responsible firm is more than trendy in the network economy. However, like with many other best practices, some businesses will adopt CSR more readily and successfully than others. As a result, some individuals dominate others. Some firms claim that CSR has a beneficial impact on their reputation, while others claim it has a detrimental impact. In light of the significance of stakeholder engagement, employee participation in CSR initiatives appears to be critical to their success (Ali et al., 2020). The firm is made up of its employees. The minority are in charge of the company's corporate strategy, while the majority are in charge of the constant effort and routines that build up the ultimate performance. Employee perceptions of all CSR initiatives, goals, and outcomes influence the company's growth and performance. The fact that CSR success is dependent upon the employee's commitments was emphasized. According to Gudaro (2012), an employee's strong corporate affiliation is predicted by the interpersonal influence image of CSR. That is why the employer branding strategy of the firm is so essential and intimately correlated to business responsibility (Awan et al., 2014). Whole theoretical connections lead to the firm's culture that defines the behaviors of its employees and strengthens the company's performance (Khan et al., 2019). The perspective of employees isn't just significant because their CSR commitment would be most vital for its implementation, alongside company leaders' participation, but mainly for better evaluating CSR practice, which is not only the traditional way of assessing CSR representatives. Based on discussed literature, the following hypothesis has been developed.

$\mathrm{H} 1=\mathrm{CSR}$ has a significant relationship with SD.

Green construction has been a hot topic in several fields in recent years, and structures that are designed and constructed in accordance with environmentally friendly principles are referred to as green buildings. It's also known as green construction. The green architecture strives to limit the number of resources consumed in building construction, usage, and operation, as well as environmental harm, through emission, pollution, and waste of its components. The design, construction, administration, and maintenance of buildings consume a lot of energy, water, and fresh materials, resulting in a lot of waste that is harmful to human health and the environment. Environmentally sound and resource-efficient structures must be built using green construction systems, which must be designed, specified, understood, and applied (Ali et al., 2021; An et al., 2021; Nawaz et al., 2021a, 2021b; Qin et al., 2021). Due to a lack of resources, the world's development needs are being met, and it's becoming clear that unless major changes in human behavior occur, civilization as we know it today is at risk. Even though sustainable development is something everyone aims for, there is no easy answer to this complex topic that can be applied to all situations without exception. The eco-friendly building design is good for the environment, society, and economy alike (Nawaz et al., 2019, 2020; Huo et al., 2021; Maqsoom et al., 2021). Based on discussed literature, the following hypothesis has been developed.

$\mathrm{H} 2=$ CSR has a significant impact on GC.

The larger vision of green construction practice, including employees, allows us to prevent the illusion of the existence of the green construction practice when the official regulation applies any sustainable development requirements. Employees' 
perspective helps to evaluate the reality of green construction practice based on the daily routines of individuals in different jobs. Tran et al. (2020) emphasized that staff expectations, intentions, opinions, or attitudes are not uniform and that a deeper understanding of employee reactions to green construction depends on the heterogeneity of their workers. It's demonstrated that the workers of their businesses are fully aware of their sustainable development activities and that they are exposed to the practice, values, and cultures both formal and informal. They have emphasized that there is currently insufficient research on employees and the CSR relationship. This approach has inspired us to extend our insight into how employees may better contribute in sustaining corporate sustainability through social advantages. The current level of knowledge extends from 2015 to the present. The major older research contains a comprehensive picture of the issue covered (Musa et al., 2020). We start with creating a wide research context. Green construction view and business behavior may vary according to various cultural perspectives. Nour and Sharabati (2019) showed that green construction implementation of the mode supply chain has the national cultural context. The adverse influence on the environmental responsibility of the masculinity factor was established by Alma'ani et al. (2019). Based on discussed literature we formulated the following hypothesis.

$\mathrm{H} 3=\mathrm{GC}$ have a significant impact on SD.

$\mathrm{H} 4$ = CSR-CI has a significant positive relationship with GC-GD.

The purchase of building materials, on the other hand, is distinct from the buying of other items. Construction procurement is defined by Carroll and Brown (2018) as "the process of purchasing products and services in order to get facilities built in line with stated specifications". A project's performance would have impact by the way it is procured. Green procurement is the practice of focusing on the environmental impact of a purchase decision. Environmental practices or initiatives or systems meant to reduce environmental consequences on their life cycle are referred to as green in construction ideas. As a result of green procurement in construction, the organization is responsible for limiting the environmental effect in construction idea of activities throughout the project's life cycle, including the building phase. Increase in average air temperatures, the earth's climate, and weather systems have undergone several modifications due to global warming. Climate change is occurring as people continue to release heat-trapping greenhouse gases (GHG) into the atmosphere (Hao et al., 2020; Huo et al., 2020; Nawaz et al., 2021b). Carbon dioxide $\left(\mathrm{CO}_{2}\right)$ is the most important anthropogenic greenhouse gas because of its abundance and ability to remain in the atmosphere for thousands of years. Construction ideas need to consider this factor. Researchers are increasingly interested in green governance concerns, which is slowly becoming the focus of government policy making. As a result, the development of green governance is sometimes clouded by unclear definitions for the duties of various disciplines and the will of the state, corporate, and private capital (Rahmawati, 2020). Current green governance techniques are generally confined to independent green manufacturing, green management, green design supply chains, and eco-friendly administration. Based on discussed literature we formulated the following hypotheses.

H5 = CSR-CI has a significant positive relationship with GC-P.

H6 = CSR-CI has a significant positive relationship with $\mathrm{CO}_{2}-\mathrm{E}$.

$\mathrm{H} 7$ = CSR-GC (governance concerns) has a significant positive relationship with GD.

In order to accomplish sustainable human and environmental development goals, it is necessary to break organizational barriers, coordinate interactions across various governance disciplines, create trust and agreement-based collaborative processes, and explore approaches of open creative governance (Nour and Sharabati, 2019). A conceptual framework for green governance is also a problem since it needs the application of principles linked to green governance, identification of all the issues that impact and are affected by green governance, and the creation of governance mechanisms, among other tasks, as well as the choice of governing methods. Temperatures in the atmosphere have increased in the last 20 years, causing a variety of changes to earth's climate and weather systems. Climate change is occurring as people continue to release heat-trapping greenhouse gases (GHG) into the atmosphere. Carbon dioxide $\left(\mathrm{CO}_{2}\right)$ is the most important anthropogenic greenhouse gas due to its abundance and ability to remain in the atmosphere for thousands of years but governance concern is the matter of fact for the 21st-century world (Rahmawati, 2020). But now, a new general strategy has appeared, promising the final answer to the world's environmental and economic woes due to this new paradigm, and both business and the environment stand to benefit. Based on discussed literature, we formulated the following hypotheses.

$\mathrm{H} 8$ = CSR-GC has a significant positive relationship with GC-P.

H9 = CSR-GC has a significant positive relationship with $\mathrm{CO}_{2}-\mathrm{E}$.

H10 = CSR-RP (reporting concern) has a significant positive relationship with GD.

Green procurement and reporting concerns are relatively related to each other. Providing a resource to the organization and workers is the responsibility of the procurement officers (Zhou et al., 2021). It's related to the reporting concern as reporting concern authorities need to know about the exact situation of the material provided and used. All aspects of the building business, including residential and non-residential constructions, are covered. For example, they are establishing and maintaining a building's structure. The building industry's resurgence has had a significant direct and indirect influence on the natural environment (Al-ma'ani et al., 2019). It is considered as one of the most significant users and producers of garbage. In addition, the building sector uses a large amount of nonrenewable energy and produces a lot of $\mathrm{CO}_{2}$ (Carroll and Brown, 2018). Philanthropic and green design are in the same direction, concepts related to human welfare (Rivo-López et al., 2021). Philanthropic groups have a straight focus on green design as it is helpful to secure human health and environmental 
protection through green design. Procurement has to be focussed on the philanthropic, and there must to arrangement and planning for philanthropic concerns. Procurement officers need to work on philanthropic because they can manage and arrange resources (Dubravská et al., 2020). Increasing the resources would increase the philanthropic; this way, environment and production would be indirect toward the green construction. Buildings account for around 39\% of worldwide $\mathrm{CO}_{2}$ emissions each year. Planning for energysaving and execution of methods to minimize potential emission mitigation should be emphasized to promote $\mathrm{CO}_{2}$ emission mitigation (Camilleri, 2017). The purpose of this article is to give an overview of the challenges, implications, and mitigation options in the construction industry for reducing and controlling $\mathrm{CO}_{2}$ emissions. Green design conserves energy, improves the well-being of occupants, and saves repair and replacement expenses during the life of the building. In addition to recycling and reusing content, green design materials lead toward sustainable construction. Keeping in view the discussed literature we developed the following hypotheses.

H11 = CSR-RP has a significant positive relationship with GP.

$\mathrm{H} 12$ = CSR-RP has a significant positive relationship with $\mathrm{CO} 2-\mathrm{E}$

$\mathrm{H} 13$ = CSR-P has a significant positive relationship with GC-GD.

$\mathrm{H} 14=\mathrm{CSR}-\mathrm{P}$ has a significant positive relationship with GC-GP.

H15 = CSR-P has a significant positive relationship with $\mathrm{CO}_{2}$-E.

H16 = GC-GD has a significant positive relationship with SD-SC.

Sustainable waste management becomes the responsibility of the company's stakeholders and green construction design. It is based on the idea that corporations have a moral duty to society and a wider social obligation. People's responses to certain social issues and their expectations of others are changing like environmental temperature can reduce due to green construction design (Wang et al., 2016). From the point of view of the sustainable construction stakeholder's green procurement is a theory of corporate ethics. It may be argued that sustainable development with green procurement has a value for shareholders. Stakeholder interest groups have grown substantially since the 1960s, and their impact on business should not be ignored. Contractors aren't interested in green procurement. In spite of this, the construction industry's engagement in green practices remains underappreciated while working on sustainable waste management (Olanipekun et al., 2021). This can be due to a lack of knowledge, competence, and interest in green procurement in the construction industry of sustainable waste management. Any construction project's procurement process is crucial to its ultimate success. Because of this, the willingness and competence of the participants in the construction sector are crucial to the successful implementation of the right procurement plan without sustainable waste management (Lu et al., 2015, 2021; Ding et al., 2018b; Kabirifar et al., 2020). This type of construction is largely helpful in the reduction of $\mathrm{CO}_{2}$ emissions. Impermanent or basic ethical principles are normative and universal notions that have always been inspired by ethics such as social fairness and human rights with sustainable waste management and protection of $\mathrm{CO}_{2}$ emission in development perspectives (Wang et al., 2016). To be a better citizen and contribute to society, a company must be responsible for sustainable waste management and $\mathrm{CO}_{2}$ emissions. According to the business ethics paradigm, sustainable waste management with $\mathrm{CO}_{2}$ emission securities is seen as social and ethical duties rather than legal and economic responsibilities. Newly installed systems are integrated with nature's existing ecosystem functions on-site through the use of ecological design. In addition, these ecological services provide habitat, adjust to solar movements, clean the air, and collect, filter, and store water, even control $\mathrm{CO}_{2}$ emissions. There are aspects that designers may use to re-create certain ecosystems. Species that thrive in natural settings may also thrive in artificial habitats that cause $\mathrm{CO}_{2}$ emissions. In order to maintain biodiversity and a healthy ecosystem, it is important to build new habitat on structures in urban areas (Nikolov, 2020). Based on above literature we devised the following hypotheses.

H17 = GC-GD has a significant positive relationship with SD-SWM.

H18 = GC-GD has a significant positive relationship with SD-ES.

H19 = GC-P has a significant positive relationship with SD-SC.

$\mathrm{H} 20$ = GC-P has a significant positive relationship with SD-SWM.

$\mathrm{H} 21$ = GC-P has a significant positive relationship with SD-ES .

$\mathrm{H} 22=\mathrm{CO}_{2}$-E has a significant positive relationship with SD-SC.

$\mathrm{H} 23=\mathrm{CO}_{2}$-E has a significant positive relationship with SD-SWM.

$\mathrm{H} 24=\mathrm{CO}_{2}$-E has a significant positive relationship with SD-ES.

\section{THEORETICAL SUPPORT AND FRAMEWORK OF THE STUDY}

As a result of considerable research, some studies have looked at how various CSR initiatives influence sustainable development and green construction. On the other hand, green construction hasn't received much attention as a factor in environmental policy. Consequently, this study explores how different forms of CSR impact sustainable development and green construction. In the study, all measures of CSR were shown to have a significant beneficial impact on sustainable development (SD) mediating green construction (GC). In addition, green construction is positively impacted sustainable development. It was observed that CSR has a higher influence on green construction and sustainable development, but CSR for consumers is a sustainable development of the environment. All indicators of CSR have a positive association with sustainable development, and CSR activities should be integrated in an organization's environmental strategy for green construction. Employees, unions, consumers, suppliers, investors, the media, competitiveness, or local communities are all stakeholders in the evolution of the stakeholder perspective related to the combination of green construction and sustainable development (Musa et al., 


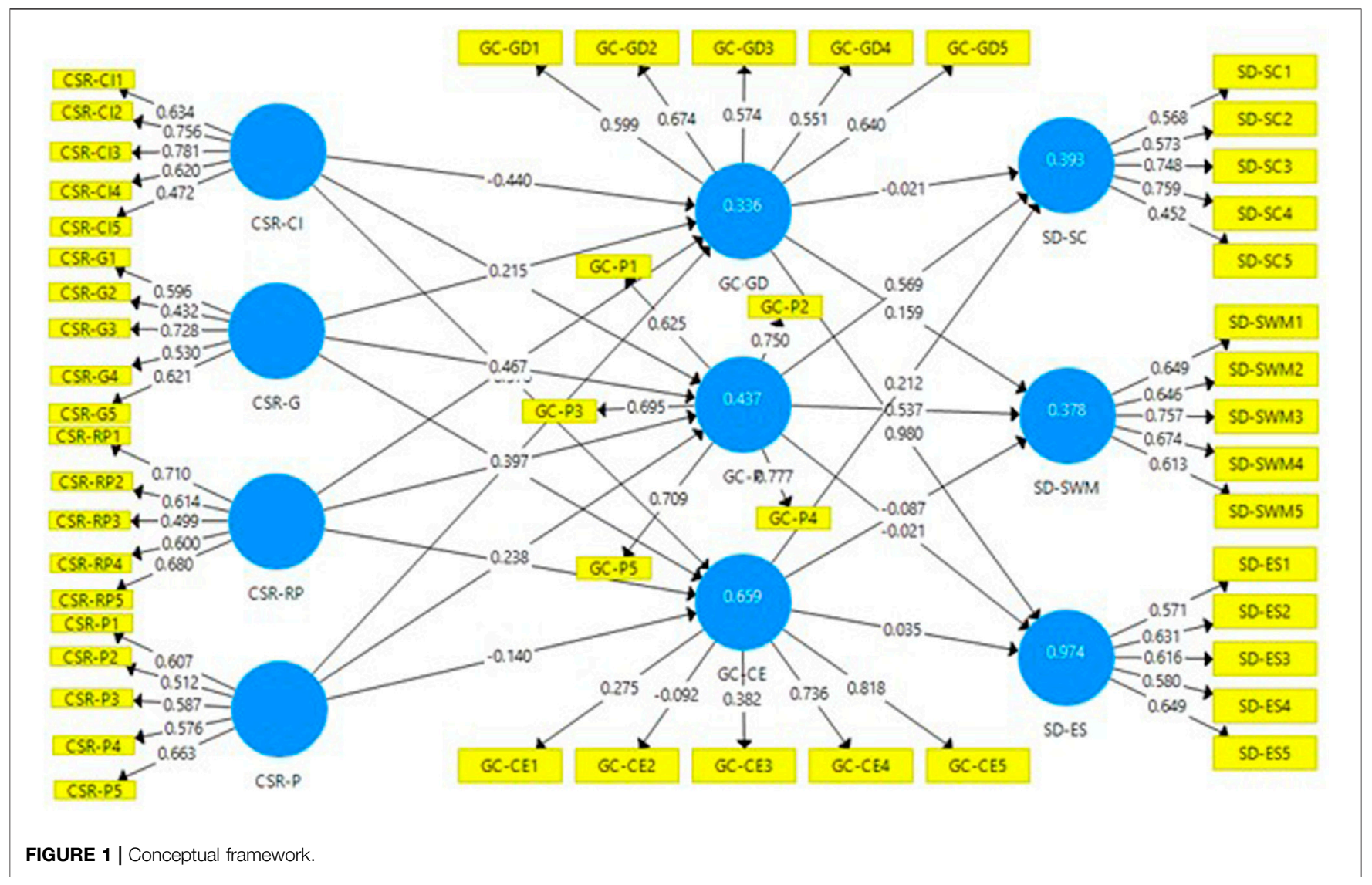

2020), for example, shareholders or owners. Customers are described as rational standardized services over the network whose behavior depends on the logical conclusions made by them regarding the events they perceive and experience. As far as CSR, green construction, and sustainable development are concerned, theories suggest that altruistic intentions can form the basis of business credibility and client attitudes toward businesses. The allocation of ideological reasons can overcome the detrimental impact on corporate credibility of low company-CSR cohesion.

The study has been distributed as the first section explains the study introduction and theoretical contribution of the study with the addition of review of literature. Research methods have been elaborated in the second section. The third section contains the data analysis, and concluding remarks have been made in the fourth section.

Based upon the literature review, this research was designed and the following conceptual framework was developed. The research revolves around this (Please see Figure 1).

\section{RESEARCH METHODS}

This research has analyzed the relationship of CSR on SD with mediating effect of GC. Research philosophy based on positivism is finding a positive relationship and promoting positivism about green construction and environment-friendly infrastructure. The hypotheses have been formulated in research to test them as deductive research design. The data have been collected from the construction firms based on their running projects from the project managers and project engineers in china. There is application of meta-analysis regression with Baron and Kenny (1986) approach for the purpose of testing mediation of green construction between sustainable development and corporate social responsibility (CSR). Simple random sampling technique was applied to collect responses upon the questionnaire, and mean randomly distributed questionnaires were used. CSR has been measured by four items (construction idea, governance concern, reporting practices, and CSR philanthropic), and these items were used by past research (Nour \& Sharabati, 2019; Nikolov, 2020; Carroll and Brown, 2018). Green construction (GC) and sustainable development (SD) have been measured by three items each, green design (GD) (Abualrejal, 2017), green procurement (P) (Rahmawati, 2020), and $\mathrm{CO}_{2}$ emission (CE) (Dahlbo et al., 2015; Wu et al., 2019). Sustainable development (SD) is based on sustainable construction (SC), sustainable waste management (SWM), and ecosystem sustainability (ES) (Abualrejal, 2017). PLS-SEM techniques have been applied to determine the direct impact of dependent and independent variables and mediation between CSR and sustainable development (SD). SEM does not require normal distribution for a small sample of study. Priorities were settled down on the bases of reliability score for components of variables. Direct impact of variables could be seen in mediation testing. To measure reliability values in SEM could be seen for 
TABLE 1 | Model measurement and descriptive analysis.

\begin{tabular}{|c|c|c|c|c|c|c|c|}
\hline Constructs & Code & FD & $a$ & CR & AVE & $\mathbf{M}$ & SD \\
\hline \multicolumn{3}{|c|}{ Corporate social responsibility (CSR) } & 0.923 & 0.918 & 0.815 & 3.98 & 0.94 \\
\hline & CSR-Cl & 0.72 & & & & & \\
\hline & CSR-GC & 0.71 & & & & & \\
\hline & CSR-RC & 0.81 & & & & & \\
\hline & CSR-P & 0.75 & & & & & \\
\hline \multicolumn{3}{|c|}{ Green Construction (GC) } & 0.851 & 0.871 & 0.895 & 3.72 & 1.09 \\
\hline & GC-GD & 0.91 & & & & & \\
\hline & GC-P & 0.69 & & & & & \\
\hline & CG-CE & 0.82 & & & & & \\
\hline \multicolumn{3}{|c|}{ Sustainable Development (SD) } & 0.725 & 0.82 & 0.757 & 3.84 & 1.04 \\
\hline & SD-SC & 0.78 & & & & & \\
\hline & SD-SWM & 0.81 & & & & & \\
\hline & SD-ES & 0.82 & & & & & \\
\hline
\end{tabular}

Note: FD, Factor Loadings; CR, Construct Reliability; AVE, Average Variance Extracted; and $\alpha$, Cronbach Alpha.

Cronbach alpha ( $\alpha$ ), along with this composite reliability has also tested the reliability and validity before testing factors impact. Normally perfect values for Cronbach alpha $(\alpha)$ should be more than 0.70 but values near 0.50 are also accepted according to (Dubravská et al., 2020) (please see Table 1; Table 2).

\section{Study Rationale for CSR and GC}

Nikolov (2020) studied that on the corporate agenda, CSR is a significant item. A firm's strategies, decision making process, and operations incorporate issues, governance risk, and social and environmental concerns. Industrial relations, reporting practices, ethics, corporate governance concerns, activities pertaining to health and safety, and commitments could be included in CSR. Previous studies have focused on employee performance and consumer attitude but neglected the importance of green builds and corporate social responsibility, construction of green buildings with LEED (leadership in energy and environment design), or CSR tools (Avotra et al., 2021).

\section{Study Rationale for GC and SD}

Nour and Sharabati (2019) explained that introducing green construction innovation could directly impact ecological wellbeing, $\mathrm{CO}_{2}$ emission, implementing environmental management, pollution prevention, and waste reduction. They further studied that green construction can increase productive, sustainable resources and cost elements directly linked to the environment. Carroll and Brown (2018) studied that implementation of green construction culture might have the ability to support the process toward sustainable developments; norms, values, and attitudinal elements related to the environment could be enhanced by supporting green culture. Sustainable design with green construction has been supported by trade associations and General Service Administration (GSA) in the United States. The construction industry came under pressure for sustainable designs and building of environment friendly constructions. According to GSA, 19 federal agencies significantly endorsed development and support of sustainable development of green construction design for both of their CSR reporting practices and CSR adoption (Ajayi et al., 2015; Bakshan et al., 2017; Ding et al., 2018a).

\section{DATA ANALYSIS}

\section{Validity and Reliability}

The primary focus of this analysis is to check and verify the reflective significance of each variable and its attached components. Starting from CSR-CI, almost four factors are reliable but the value of CSR-CI5 is lower than 0.50 ; values more than 0.70 are perfect but research can compromise on values above 0.50 in certain conditions. Here values for CSR-CI2 and CSR-CI3 are perfectly significant. Observing the reliability values for CSR-G, here the condition is little bit worrying; only CSR-G3 have significant values for 0.728 , and all other values are less than a significance level of 0.70 . The values with lower reliability score would be removed in an adjusted model (please see Figure 3). Testing reliability for CSR and its component CSR-RP, almost three values are at acceptable level. Values for CSR-RP1, CSR-RP2, CSR-RP3, CSR-RP4, and CSR-RP5 are 0.71, 0.61, 0.49, 0.60, and 0.68 (please see Figure 1); it's likely to remove CSR-RP3 to make clear sense of reliability and validity. It's seen that CSR-P have miserable condition, and not a single element has reliability values more than 0.70 , but values for CSR-P1 and CSR-P5 could be part of analysis on certain conditions. All independent variables have significant reliability and could be tested for mediations. Mediating variables like GC-GD, GC-P, and GC-CE have been tested for reliability and validity. GC-GD2 and GC-GD5 are perfect, but all their components are also reasonably acceptable. But in case of GC-GD, there would be removal of all value less than 0.50 like

TABLE 2 | Mediating relationship between variables.

\begin{tabular}{|c|c|c|}
\hline Steps & Analysis & Visual Description \\
\hline Step 1 & Simple regression (without mediation) & CSR ------ $\rightarrow$ SD \\
\hline & $S D=a+b(C S R)+e$ & CSR will predict SD \\
\hline Step 2 & Mediation testing: Prediction of mediator GC (as DV) by independent variable, GC $=a+b(C S R)+e$ & $\begin{array}{l}\text { CSR }-----\rightarrow \text { GC } \\
\text { CSR will predict GC }\end{array}$ \\
\hline Step 3 & $\begin{array}{l}\text { Mediation testing: Prediction of SD by } G C \\
S D=a+b(G C)+e\end{array}$ & $\begin{array}{l}\mathrm{GC}-----\rightarrow \text { SD } \\
\mathrm{GC} \text { will predict SD }\end{array}$ \\
\hline Step 4 & $\begin{array}{l}\text { Conducting multiple regression by CSR and CG predicting SD } \\
\mathrm{SD}=\mathrm{a}+\mathrm{b} 1(\mathrm{CSR})+\mathrm{b} 2(\mathrm{GC})+\mathrm{e}\end{array}$ & $\begin{array}{l}\text { CSR }-\cdots \rightarrow \text { SD } \\
\text { GC }-\cdots-\cdots \text { SD }\end{array}$ \\
\hline
\end{tabular}



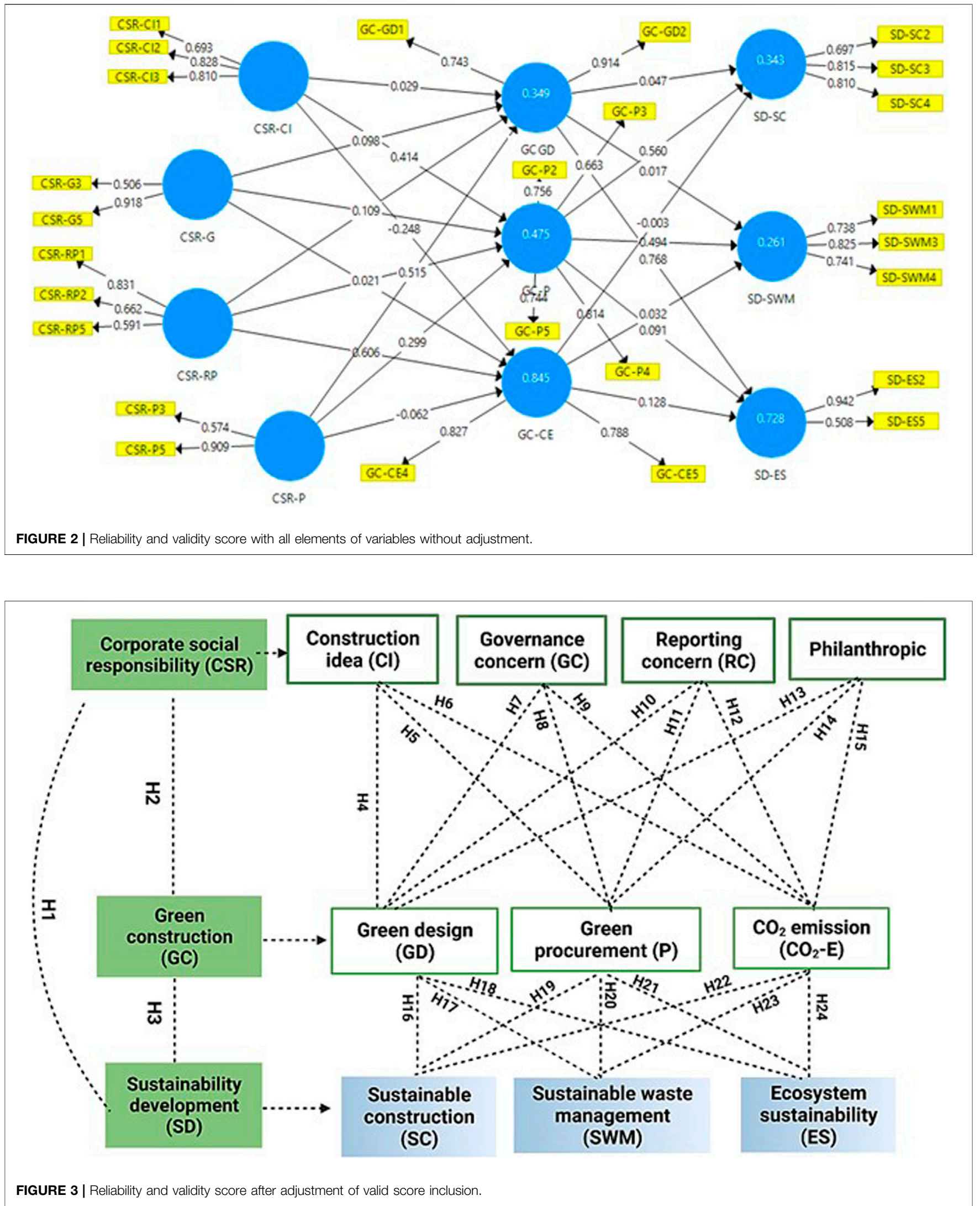
TABLE 3 | Values for $r$ square and adjusted $r$ square.

\begin{tabular}{lcc} 
& R Square & R Square adjusted \\
\hline GC-CE & 0.845 & 0.843 \\
GC-GD & 0.349 & 0.341 \\
GC-P & 0.475 & 0.469 \\
SD-ES & 0.728 & 0.726 \\
SD-SC & 0.343 & 0.337 \\
SD-SWM & 0.261 & 0.254
\end{tabular}

GC-GD1, GC-GD3, and GC-GD4 to make other variables' reliability higher. In case of GC-P, its observed that values for GC-P4, GC-P2, and GC-P3 are perfectly significant, and a lower case of reliability has been removed in the revised model (please see Figure 3). For GC-CE, it has been seen that values of GC-CE2, GC-CE3, and GC-CE1 are lowest in the model (please see Figure 2). Values for GC-CE4 and GC-CE5 are strongly reliable for final analysis of mediation.

Like independent variables, all dependent variables have good reliability values if lower case would be removed. Sustainable development has three components like SD-SC, SD-SWM, and SD-ES. SD-SE have one lower case value for SD-SE5 with reliability score of 0.45 . One element for SD-SWM would be suggested to be removed to increase the reliability score for other components and it would be SD-SWM5 (please see Figure 2), but SD-SWM2 was also required to be removed to make SD-SWM1, SD-SWM3, and SD-SWM4 perfectly significant, and it could be seen in Figure 3. SD-ES is more sensitive because its reliability values are also lower like CSR-P, so lower values like SD-ES4 (0.58), SD-ES (0.57), and SD-ES3 (0.616) were removed.

Figure 2 has been revised to obtain a perfect least possible model for impact factor analysis and to test the interdependence of the variables. Lower components like CSR-CI4 and CSR-CI5, CSR-G1, CSR-G2 and CSR-G3, CSR-RP3, CSR-RP4 along with CSR-P1, CSR-P2, and CSR-P4 have been removed. After removal of lower-case CSR-CI, we have maintained three elements out of five. CSR-CI have the best possible reliabilities like CSR-CI1 (0.693), CSR-CI2 (0.828), and CSR-CI3 (0.81) to test the mediation. CSR-G has two reliable components, CSR-RP have computed three reliable components, and only two components for CSR-P, GC-CE, SD-ES, CSR-G, and GC-GD have been selected in revised model for final analysis. Reliability scores have been improved from 0.59 to 0.64 to 0.74 and 0.91 for CG-GD and GC-GD in the revised model (please see Figure 3). Reliability scores for GC-P2, GC-P4, and GC-P5 have been improvised up to $0.75,0.81$, and 0.74 respectively. Perfect reliability has been extracted in revised models for GCCE4 and GC-CE5 with 0.82 and 0.78 respectively. Perfect and significant reliability have been achieved in the revised model for SD-SC and SD-SWM with higher values than 0.70 , but in the case of SD-ES, one component has lower reliability with score of 0.50 and other elements have higher significant reliability with a value of 0.94 . To prepare for construct reliability, composite reliability is the first step of measurement according to Al-ma'ani et al. (2019) for the purpose of measurement internal consistency between variables. Cronbach alpha is an appropriate
TABLE 4 | Multicollinearity of variables.

\begin{tabular}{|c|c|}
\hline Variable's component & VIF \\
\hline CSR-Cl1 & 1.349 \\
\hline CSR-Cl2 & 1.305 \\
\hline CSR-Cl3 & 1.368 \\
\hline CSR-G3 & 1.015 \\
\hline CSR-G5 & 1.015 \\
\hline CSR-P3 & 1.033 \\
\hline CSR-P5 & 1.033 \\
\hline CSR-RP1 & 1.146 \\
\hline CSR-RP2 & 1.106 \\
\hline CSR-RP5 & 1.087 \\
\hline GC-CE4 & 1.102 \\
\hline GC-CE5 & 1.102 \\
\hline GC-GD1 & 1.199 \\
\hline GC-GD2 & 1.199 \\
\hline GC-P2 & 1.522 \\
\hline GC-P3 & 1.299 \\
\hline GC-P4 & 1.673 \\
\hline GC-P5 & 1.312 \\
\hline SD-ES2 & 1.037 \\
\hline SD-ES5 & 1.037 \\
\hline SD-SC2 & 1.359 \\
\hline SD-SC3 & 1.281 \\
\hline SD-SC4 & 1.351 \\
\hline SD-SWM1 & 1.286 \\
\hline SD-SWM3 & 1.351 \\
\hline SD-SWM4 & 1.228 \\
\hline
\end{tabular}

measurement tool, and basically its measurement is related to how closely variables are related to each other for a set of grouped items based on a framework model. It is necessary to maintain values for PLS-SEM analysis reliability up to 0.70 according to Dijkstra and Henseler (2015), but some other authors like Khaver (2019) suggested that it could be supposed to be good above 0.50 .

\section{Explained Variations and Multicollinearity}

For validation of structural model, $\mathrm{R}$ square and adjusted $\mathrm{R}$ square define criteria for validation of hypothesis based on path coefficient. $\mathrm{R}$ square is also known as coefficient of determinant; its acceptable results range from 0.25 to 0.75 . Values for 0.25 are considered week, moderate for 0.50 , and substantial for 0.75 according to Rivo-López et al. (2021). R square defines explained variations. Table 1 shows that explained variation for GC-CE extracted 0.84 that means model for regression have been explained up to $84 \%$. GC-GD and SD-SC have week model explanation up to 0.34 or $34 \%$ for both variables. SD-SWM have the lowest explanation up to $26 \%$. Values for adjusted $\mathrm{R}$ square are not much different from $\mathrm{R}$ square. Highest explanation of regression model has been observed in the case of SD-SC and GC-CE. Moderate model explanation for GC-P have been analyzed up to 0.47 (Table 3).

Substantial degree of accuracy has been observed by VIF applying multicollinearity, and value for VIF remains between 1 and 10 . Value near 10 means that chances of multicollinearity and accuracy for results could be in trouble. But values near one means that accuracy of result is higher. Here values for VIF in Table 4 show that accuracy of results is perfect and significant for all variables and its components from CSR-CI to SD-SWM. The 
TABLE 5 | Path coefficients.

\begin{tabular}{|c|c|c|c|c|c|c|}
\hline Relationship & $\begin{array}{l}\text { Original Sample } \\
\text { (O) }\end{array}$ & $\begin{array}{c}\text { Sample Mean } \\
\text { (M) }\end{array}$ & $\begin{array}{c}\text { Standard Deviation } \\
\text { (STDEV) }\end{array}$ & $\begin{array}{l}\text { T Statistics } \\
\text { (|O/STDEV|) }\end{array}$ & $p$ Values & Decision \\
\hline CSR-Cl -> GC-CE & -0.248 & -0.243 & 0.061 & 4.070 & 0.000 & Accepted \\
\hline CSR-Cl -> GC-GD & 0.029 & 0.031 & 0.072 & 0.403 & 0.344 & Rejected \\
\hline CSR-Cl -> GC-P & 0.414 & 0.421 & 0.064 & 6.497 & 0.000 & Accepted \\
\hline CSR-G -> GC-CE & 0.558 & 0.560 & 0.044 & 12.712 & 0.000 & Accepted \\
\hline CSR-G -> GC-GD & 0.098 & 0.098 & 0.052 & 1.878 & 0.030 & Accepted \\
\hline CSR-G -> GC-P & 0.207 & 0.207 & 0.054 & 3.863 & 0.000 & Accepted \\
\hline CSR-P -> GC-CE & -0.062 & -0.059 & 0.029 & 2.098 & 0.018 & Accepted \\
\hline CSR-P $\rightarrow$ GC-GD & 0.515 & 0.512 & 0.059 & 8.802 & 0.000 & Accepted \\
\hline CSR-P -> GC-P & 0.299 & 0.296 & 0.056 & 5.326 & 0.000 & Accepted \\
\hline CSR-RP -> GC-CE & 0.606 & 0.606 & 0.056 & 10.835 & 0.000 & Accepted \\
\hline CSR-RP -> GC-GD & 0.109 & 0.107 & 0.061 & 1.788 & 0.037 & Accepted \\
\hline CSR-RP -> GC-P & 0.021 & 0.017 & 0.061 & 0.353 & 0.362 & Rejected \\
\hline GC-CE -> SD-ES & 0.128 & 0.126 & 0.038 & 3.328 & 0.000 & Accepted \\
\hline GC-CE -> SD-SC & -0.003 & -0.004 & 0.050 & 0.059 & 0.477 & Rejected \\
\hline GC-CE -> SD-SWM & 0.032 & 0.032 & 0.053 & 0.612 & 0.270 & Rejected \\
\hline GC-GD -> SD-ES & 0.768 & 0.770 & 0.050 & 15.458 & 0.000 & Accepted \\
\hline GC-GD -> SD-SC & 0.047 & 0.043 & 0.066 & 0.710 & 0.239 & Rejected \\
\hline GC-GD -> SD-SWM & 0.017 & 0.016 & 0.062 & 0.280 & 0.390 & Rejected \\
\hline GC-P -> SD-ES & 0.091 & 0.090 & 0.046 & 1.995 & 0.023 & Accepted \\
\hline GC-P -> SD-SC & 0.560 & 0.567 & 0.057 & 9.804 & 0.000 & Accepted \\
\hline GC-P -> SD-SWM & 0.494 & 0.498 & 0.065 & 7.561 & 0.000 & Accepted \\
\hline
\end{tabular}

TABLE 6 | Total indirect effect (without mediation).

\begin{tabular}{|c|c|c|c|c|c|c|}
\hline Relationship & $\begin{array}{l}\text { Original Sample } \\
\text { (O) }\end{array}$ & $\begin{array}{c}\text { Sample Mean } \\
\text { (M) }\end{array}$ & $\begin{array}{c}\text { Standard Deviation } \\
\text { (STDEV) }\end{array}$ & $\begin{array}{l}\text { T Statistics } \\
\text { (|O/STDEV|) }\end{array}$ & $p$ Values & Decision \\
\hline CSR-Cl -> SD-ES & 0.028 & 0.030 & 0.060 & 0.472 & 0.319 & Rejected \\
\hline CSR-Cl -> SD-SC & 0.234 & 0.245 & 0.052 & 4.535 & 0.000 & Accepted \\
\hline CSR-Cl -> SD-SWM & 0.197 & 0.204 & 0.044 & 4.458 & 0.000 & Accepted \\
\hline CSR-G -> SD-ES & 0.165 & 0.165 & 0.048 & 3.457 & 0.000 & Accepted \\
\hline CSR-G -> SD-SC & 0.119 & 0.118 & 0.045 & 2.673 & 0.004 & Accepted \\
\hline CSR-G -> SD-SWM & 0.122 & 0.123 & 0.044 & 2.763 & 0.003 & Accepted \\
\hline CSR-P -> SD-ES & 0.415 & 0.413 & 0.048 & 8.677 & 0.000 & Accepted \\
\hline CSR-P -> SD-SC & 0.192 & 0.188 & 0.041 & 4.635 & 0.000 & Accepted \\
\hline CSR-P -> SD-SWM & 0.155 & 0.153 & 0.042 & 3.702 & 0.000 & Accepted \\
\hline CSR-RP -> SD-ES & 0.163 & 0.160 & 0.055 & 2.943 & 0.002 & Accepted \\
\hline CSR-RP -> SD-SC & 0.015 & 0.012 & 0.039 & 0.392 & 0.348 & Rejected \\
\hline CSR-RP -> SD-SWM & 0.032 & 0.029 & 0.039 & 0.820 & 0.206 & Rejected \\
\hline
\end{tabular}

range of values for VIF lies between 1.03 and 1.67, means lower value up to 1.03 for SD-ES5, CSR-P2, and CSR-P5, and higher value up to 1.67 for GC-P. Conclusively VIF proved that results have perfect accuracy related to multicollinearity (Table 4).

\section{Relationship Measurement}

Path coefficients define the significance and insignificance of the variable's relationship. Table 5 defines the strength of the relationship; original sample means represent value for coefficients. The strength of relationship is largely based on coefficients value. In case of relationship between CSR-CI and GC-CE, value of coefficient shows that there is negative significant relationship. Dependence of GC-GD on CSR-CI has been rejected on the basis of $p$ value as $p$ value is higher than level of significance 0.05 . Accepted relationships include CSR-G -> GC-CE, CSR-G -> GC-GD, CSR-G -> GC-P, CSR-P -> GC-CE,
CSR-P -> GC-GD, CSR-P -> GC-P, CSR-RP -> GC-CE, CSR-RP $->$ GC-GD, GC-CE -> SD-ES, GC-GD -> SD-ES, GC-P -> SD-ES, GC-P -> SD-SC and GC-P -> SD-SWM. Some of the accepted relationships include negative values of sample mean/coefficient including CSR-CI -> GC-CE, CSR-P -> GC-CE and GC-CE -> SD-SC. Variables with week strength of relationships have lower values of sample mean/coefficients but stronger values of sample means, which shows that strength of relationship is perfectly significant either negative or positive (Table 5).

Total indirect effect has been observed in Table 6, indirect effect measures the level of significant without mediating effect of green construction (GC). Again, for lower values of sample mean or coefficient measure the strength of relationship. Value of coefficient measure that how strongly dependent variable have been attached to the independent variable. For selected relationships CSR-CI -> SD-ES (0.319), CSR-RP $->$ SD-SC 
TABLE 7 | Mediation testing and measurement of relationship between variables.

\begin{tabular}{|c|c|c|c|c|c|}
\hline Hypothesis & $\begin{array}{l}\text { Original Sample } \\
\text { (O) }\end{array}$ & $\begin{array}{c}\text { Sample Mean } \\
\text { (M) }\end{array}$ & $\begin{array}{c}\text { Standard deviation } \\
\text { (STDEV) }\end{array}$ & $\begin{array}{l}\text { T Statistics } \\
\text { (|O/STDEV|) }\end{array}$ & $p$ Values \\
\hline CSR-Cl -> GC-CE & -0.248 & -0.243 & 0.061 & 4.070 & 0.000 \\
\hline CSR-Cl -> GC-GD & 0.029 & 0.031 & 0.072 & 0.403 & 0.344 \\
\hline CSR-Cl -> GC-P & 0.414 & 0.421 & 0.064 & 6.497 & 0.000 \\
\hline CSR-G -> GC-CE & 0.558 & 0.560 & 0.044 & 12.712 & 0.000 \\
\hline CSR-G -> GC-GD & 0.098 & 0.098 & 0.052 & 1.878 & 0.030 \\
\hline CSR-G -> GC-P & 0.207 & 0.207 & 0.054 & 3.863 & 0.000 \\
\hline CSR-P -> GC-CE & -0.062 & -0.059 & 0.029 & 2.098 & 0.018 \\
\hline CSR-P -> GC-GD & 0.515 & 0.512 & 0.059 & 8.802 & 0.000 \\
\hline CSR-P -> GC-P & 0.299 & 0.296 & 0.056 & 5.326 & 0.000 \\
\hline CSR-RP -> GC-CE & 0.606 & 0.606 & 0.056 & 10.835 & 0.000 \\
\hline CSR-RP -> GC-GD & 0.109 & 0.107 & 0.061 & 1.788 & 0.037 \\
\hline CSR-RP -> GC-P & 0.021 & 0.017 & 0.061 & 0.353 & 0.362 \\
\hline GC-CE -> SD-ES & 0.128 & 0.126 & 0.038 & 3.328 & 0.000 \\
\hline GC-CE -> SD-SC & -0.003 & -0.004 & 0.050 & 0.059 & 0.477 \\
\hline GC-CE -> SD-SWM & 0.032 & 0.032 & 0.053 & 0.612 & 0.270 \\
\hline GC-GD -> SD-ES & 0.768 & 0.770 & 0.050 & 15.458 & 0.000 \\
\hline GC-GD -> SD-SC & 0.047 & 0.043 & 0.066 & 0.710 & 0.239 \\
\hline GC-GD -> SD-SWM & 0.017 & 0.016 & 0.062 & 0.280 & 0.390 \\
\hline GC-P $\rightarrow$ SD-ES & 0.091 & 0.090 & 0.046 & 1.995 & 0.023 \\
\hline GC-P -> SD-SC & 0.560 & 0.567 & 0.057 & 9.804 & 0.000 \\
\hline GC-P -> SD-SWM & 0.494 & 0.498 & 0.065 & 7.561 & 0.000 \\
\hline
\end{tabular}

(0.346), CSR-RP -> SD-SWM (0.206) are insignificant, due to lower sample mean values. Sample means or coefficient values are 0.03 for CSR-CI -> SD-ES, 0.01 for CSR-RP -> SD-SC and 0.02 for CSR-RP $->$ SD-SWM (Table 6).

Significant $p$ values show higher coefficient values in Table 6 as CSR-CI -> SD-SC (0.245) CSR-CI -> SD-SWM (0.204), CSR-G $\rightarrow$ SD-ES (0.165), CSR-G -> SD-SC (0.118), CSR-G -> SD-SWM (0.123), CSR-P $\rightarrow$ SD-ES (0.413), CSR-P $\rightarrow$ SD-SC0 (0.188), CSR-P -> SD-SWM (0.155) and CSR-RP -> SD-ES (0.160), and these values are statistically significant.

\section{Results to Test Mediation}

After testing direct relationship of dependent and independent variable, its time to observe the mediation between variables. Sample test for hypothesis from $\mathrm{H} 4$ to $\mathrm{H} 24$ could be seen that H5, H6, H7, H8, H9, H11, H12, H13 H14, H15, H18, H19, H20, $\mathrm{H} 21$, and $\mathrm{H} 24$ are accepted on the basis of significant $p$ values as significant values for these hypotheses. These relationships are interdependently significant to each other, like CSR-CI with GC-CE, CSR-CI with GC-P, and so which have significant values less than 0.05 . Rejected hypothesis are $\mathrm{H} 4, \mathrm{H} 10, \mathrm{H} 22$, $\mathrm{H} 23, \mathrm{H} 16$, and H17. All mediations related to these hypotheses are also rejected. Mediation needs relationship on both direction, mediation being dependent or independent must need to be significant to prove its mediating impact (Tables 7, 8).

CSR has significant mediating effect on sustainable development (SD). Mediation relationship related to green construction (GC), $\mathrm{CO}_{2}$ emission (CE) linked with sustainable construction (SC), and sustainable waste management (SWM) have been rejected because green construction (GC) and $\mathrm{CO}_{2}$ emission (CE) are insignificant with sustainable construction (SC) and sustainable waste management (SWM).
TABLE 8 | Hypothesis acceptance and rejection.

\begin{tabular}{|c|c|c|}
\hline Hypothesis & & Decision \\
\hline CSR-Cl -> GC-CE & $\mathrm{H} 6$ & Accepted \\
\hline CSR-Cl -> GC-GD & $\mathrm{H} 4$ & Rejected \\
\hline CSR-Cl -> GC-P & $\mathrm{H} 5$ & Accepted \\
\hline CSR-G -> GC-CE & H9 & Accepted \\
\hline CSR-G -> GC-GD & $\mathrm{H} 7$ & Accepted \\
\hline CSR-G -> GC-P & $\mathrm{H} 8$ & Accepted \\
\hline CSR-P -> GC-CE & $\mathrm{H} 15$ & Accepted \\
\hline CSR-P -> GC-GD & $\mathrm{H} 13$ & Accepted \\
\hline CSR-P -> GC-P & $\mathrm{H} 14$ & Accepted \\
\hline CSR-RP -> GC-CE & $\mathrm{H} 12$ & Accepted \\
\hline CSR-RP -> GC-GD & $\mathrm{H} 11$ & Accepted \\
\hline CSR-RP -> GC-P & $\mathrm{H} 10$ & Rejected \\
\hline GC-CE -> SD-ES & $\mathrm{H} 24$ & Accepted \\
\hline GC-CE -> SD-SC & $\mathrm{H} 22$ & Rejected \\
\hline GC-CE -> SD-SWM & $\mathrm{H} 23$ & Rejected \\
\hline GC-GD -> SD-ES & $\mathrm{H} 18$ & Accepted \\
\hline GC-GD $>$ SD-SC & $\mathrm{H} 16$ & Rejected \\
\hline GC-GD -> SD-SWM & $\mathrm{H} 17$ & Rejected \\
\hline GC-P -> SD-ES & $\mathrm{H} 21$ & Accepted \\
\hline GC-P -> SD-SC & $\mathrm{H} 19$ & Accepted \\
\hline GC-P -> SD-SWM & $\mathrm{H} 2 \mathrm{O}$ & Accepted \\
\hline CSR $->$ SD & $\mathrm{H} 1$ & Accepted \\
\hline CSR $->$ GC & $\mathrm{H} 2$ & Accepted \\
\hline $\mathrm{GC}->\mathrm{SD}$ & $\mathrm{H} 3$ & Accepted \\
\hline
\end{tabular}

Possible accepted mediation relationships have been listed in Table 9 here CSR-CI are statistically significant with GC-CE and further, this variable is again statistically significant with SD-SE. This way three other relationships of CSR-CI are significant as GC-P is significant with all three components of SD (SC, CWM, ES). Only one significant relationship has been observed mediating $\mathrm{CO}_{2}$ emission. $\mathrm{CE}$ or $\mathrm{CO}_{2}$ emission mediates between CSR-GC, SD, and E. 
TABLE 9 | Acceptance and Rejection of mediation.

\begin{tabular}{|c|c|}
\hline Mediation relationship & Decision \\
\hline CSR-Cl -> GC-CE -> SD-ES & Accepted \\
\hline CSR-Cl -> GC-P -> SD-SC & Accepted \\
\hline CSR-Cl -> GC-P -> SD-SWM & Accepted \\
\hline CSR-Cl -> GC-P -> SD-ES & Accepted \\
\hline CSR-G -> GC-CE -> SD-ES & Accepted \\
\hline CSR-G -> GC-GD $->$ SD-ES & Accepted \\
\hline CSR-G -> GC-P -> SD-SC & Accepted \\
\hline CSR-G -> GC-P -> SD-SWM & Accepted \\
\hline CSR-G -> GC-P -> SD-ES & Accepted \\
\hline CSR-P $->$ GC-CE $->$ SD-ES & Accepted \\
\hline CSR-P $->$ GC-GD $->$ SD-ES & Accepted \\
\hline CSR-P -> GC-P -> SD-SC & Accepted \\
\hline CSR-P -> GC-P -> SD-SWM & Accepted \\
\hline CSR-P -> GC-P -> SD-ES & Accepted \\
\hline CSR-RP -> GC-P -> SD-SC & Accepted \\
\hline CSR-RP -> GC-P -> SD-SWM & Accepted \\
\hline CSR-RP -> GC-P -> SD-ES & Accepted \\
\hline
\end{tabular}

Green construction design (GC-GD) mediates between CSR-GC and sustainable ecosystem (SE). Most significant and reliable mediator proved green procurement (GC-P), as green construction procurement mediates between CSR governance concern (CSR-GC) and all three elements (sustainable construction (SC), construction waste management (CWM), and ecosystem sustainability (ES) of sustainable development (SD). Further, green construction design (GC-GD) and green construction- $\mathrm{CO}_{2}$ emission (GC-CE) mediate between sustainable development ecosystem (SD-ES) and CSR-philanthropic (CSR-P). Again, green contraction procurement (GC-P) mediations between CSR-philanthropic (CSR-P) and three components (sustainable construction [SD], sustainable waste management [SWM], and sustainable ecosystem [SE]) of sustainable development (SD). At the end, green construction procurement (GC-P) mediates (CSR-RP) reporting practices and all three components of sustainable development (SD).

\section{CONCLUSION AND STUDY IMPLICATION}

Green construction is important to reduce the world's temperature as emission of greenhouse gases and large construction buildings are occupying forest and cutting trees. For constraining builders, addition of CSR in their job description would largely impact on problems solutions. CSR can impact sustainable development, but the addition of green construction as a mediating factor would have a significant impact. So, this paper has studied the meditating impact of green construction (GC) between CSR and sustainable development (SD). The basic goal of this study was to find out the significant relationship between CSR and GC and further to link green construction (GC) with sustainable development (SD). Results indicate that green procurement as a component of green construction strongly mediates between corporate social responsibility and sustainable development, while green design and CO2 emission moderately mediate between corporate social responsibility and sustainable development. This study found that CSR philanthropic has overall significance from all four components of CSR, green procurement from green construction components, and all three components of sustainable development including sustainable construction, sustainable waste management, and sustainable ecosystem are significant with green procurement and CSR philanthropic. In addition, CSR construction ideas (CSR-CI) are significant with green construction, $\mathrm{CO}_{2}$ emission, and CSR construction ideas with green construction procurement. CSR philanthropic is statistically significant with green construction design, CSR philanthropic with green construction procurement (GC-P), green construction procurement with sustainable development ecosystem (SD-ES), sustainable construction, and sustainable waste management (SC-SWM). Green construction design (GC-GD) has mediation impact between sustainable ecosystem and governance concern (SE-GC). Green procurement mediates upon CSR governance and sustainable development (all three elements: ecosystem sustainability [ES] and sustainable waste management and construction [SWM$\mathrm{SC}]$ ). Further, green construction design (GC-GD) and green construction- $\mathrm{CO}_{2}$ emission (GC-CE) mediate between sustainable development ecosystem (SD-ES) and CSRphilanthropic (CSR-P). Again, green contraction procurement mediations between CSR-philanthropic and three components (sustainable construction, sustainable waste management and ecosystem) of sustainable development. At the end, green construction procurement (GC-P) mediates CSR-reporting practices and all three components of sustainable development (SD).

\section{LIMITATION OF THE STUDY}

This study is limited to investigating the relationship between CSR with green construction and sustainability development. It has been utilized in the Chinese construction atmosphere and the respondents were Chinese engineers and project managers working on different diverse projects. In the future it can be investigated in different states having different construction infrastructure by adding more environmental, construction, and human resource factors.

\section{DATA AVAILABILITY STATEMENT}

The original contributions presented in the study are included in the article/Supplementary Material, and further inquiries can be directed to the corresponding authors.

\section{ETHICS STATEMENT}

The studies involving human participants were reviewed and approved by the Zhejiang Wanli University China. The 
participants provided their written informed consent to participate in this study.

\section{AUTHOR CONTRIBUTIONS}

AA, YC conceived and designed the concept, literature review, data collection and wrote the paper. WY, ZL helped to provide technical support, contributed in analysis tools. AN has reviewed

\section{REFERENCES}

Abualrejal, H. M. (2017). Green Building Toward Construction Sustainability Energy. J. Tech.Opera. Manag. 100, 100-109.

Ajayi, S. O., Oyedele, L. O., Bilal, M., Akinade, O. O., Alaka, H. A., Owolabi, H. A., et al. (2015). Waste Effectiveness of the Construction Industry: Understanding the Impediments and Requisites for Improvements. Resour. Conservation Recycling 102, 101-112. doi:10.1016/j.resconrec.2015.06.001

Al-ma'ani, B., Al-Qudah, S., and Shrouf, H. (2019). The Impact of Corporate Social Responsibility on Organizational Performance in Telecommunication Sector in Jordan. Mas 13, 1. doi:10.5539/mas.v13n4p1

Ali, L., Nawaz, A., Iqbal, S., Basheer, M. A., Hameed, J., Albasher, G., et al. (2021). Dynamics of Transit Oriented Development, Role of Greenhouse Gases and Urban Environment : A Study for Management and Policy. Sustain. 13, 2536. 10.3390/su13052536

Ali, S. L., Farooq, A., and Gillani, S. S. (2020). Impact of Globalization and Foreign Direct Investment on Economic Growth : Empirical Evidences from Pakistan. J. Glob. Econ. 8, 3. doi:10.37421/economics.2020.8.348

An, H., Razzaq, A., Nawaz, A., Noman, S. M., and Khan, S. A. R. (2021). Nexus between green Logistic Operations and Triple Bottom Line: Evidence from Infrastructure-Led Chinese Outward Foreign Direct Investment in Belt and Road Host Countries. Environ. Sci. Pollut. Res. 28, 51022-51045. doi:10.1007/ s11356-021-12470-3

Avotra, A. A. R. N., Chengang, Y., Sandra Marcelline, T. R., Asad, A., and Yingfei, Y. (2021). Examining the Impact of E-Government on Corporate Social Responsibility Performance: The Mediating Effect of Mandatory Corporate Social Responsibility Policy, Corruption, and Information and Communication Technologies Development during the COVID Era. Front. Psychol. 12, 4221. doi:10.3389/fpsyg.2021.737100

Awan, A. G., Ahmad, W., Shahid, P., and Hassan, J. (2014). Factors Affecting Foreign Direct Investment in Pakistan. Int. J. Bus. Manag. Rev. 2, 21-35. doi:10.1016/S01689002(01)01865-4

Bakshan, A., Srour, I., Chehab, G., El-Fadel, M., and Karaziwan, J. (2017). Behavioral Determinants towards Enhancing Construction Waste Management: A Bayesian Network Analysis. Resour. Conservation Recycling 117, 274-284. doi:10.1016/j.resconrec.2016.10.006

Baron, R. M., and Kenny, D. A. (1986). The Moderator-Mediator Variable Distinction in Social Psychological Research: Conceptual, Strategic, and Statistical Considerations. J. Personal. Soc. Psychol. 51, 1173-1182. doi:10.1037//0022-3514.51.6.1173

Camilleri, M. A. (2017). "The Corporate Social Responsibility Notion," in Corporate Sustainability, Social Responsibility and Environmental Management. (Cham: Springer). doi:10.1007/978-3-319-46849-5

Carroll, A. B., and Brown, J. A. (2018). Corporate Social Responsibility: A Review of Current Concepts, Research, and Issues. Res., Issues 2, 39-69. doi:10.1108/ S2514-175920180000002002

Dahlbo, H., Bachér, J., Lähtinen, K., Jouttijärvi, T., Suoheimo, P., Mattila, T., et al. (2015). Construction and Demolition Waste Management - a Holistic Evaluation of Environmental Performance. J. Clean. Prod. 107, 333-341. doi:10.1016/j.jclepro.2015.02.073

Dijkstra, T. K., and Henseler, J. (2015). Consistent Partial Least Squares Path Modeling. Misq 39, 297-316. doi:10.25300/MISQ/2015/39.2.02

Ding, Z., Gong, W., Li, S., and Wu, Z. (2018a). System Dynamics versus Agent-Based Modeling: A Review of Complexity Simulation in the work to improve the outcomes. All authors have read and agreed to the published version of the manuscript.

\section{FUNDING}

General Project of National Social Science Foundation of ChinaResearch on Mechanism and Path of National Audit to resolve systemic financial risks (20BGL079).

Construction Waste Management. Sustainability 10, 2484. doi:10.3390/ su 10072484

Ding, Z., Zhu, M., Tam, V. W. Y., Yi, G., and Tran, C. N. N. (2018b). A System Dynamics-Based Environmental Benefit Assessment Model of Construction Waste Reduction Management at the Design and Construction Stages. J. Clean. Prod. 176, 676-692. doi:10.1016/ j.jclepro.2017.12.101

Dubravská, M., Marchevská, M., Vašaničová, P., and Kotulič, R. (2020). Corporate Social Responsibility and Environmental Management Linkage: An Empirical Analysis of the Slovak Republic. Sustainability 12, 5431-5518. doi:10.3390/ su12135431

Elahi, E., Abid, M., Zhang, L., Ul Haq, S., and Sahito, J. G. M. (2018). Agricultural Advisory and Financial Services; Farm Level Access, Outreach and Impact in a Mixed Cropping District of Punjab, Pakistan. Land use policy 71, 249-260. doi:10.1016/j.landusepol.2017.12.006

Elahi, E., Khalid, Z., Tauni, M. Z., Zhang, H., and Lirong, X. (2021). Extreme Weather Events Risk to Crop-Production and the Adaptation of Innovative Management Strategies to Mitigate the Risk: A Retrospective Survey of Rural Punjab, Pakistan. Technovation 2021, 102255. doi:10.1016/ j.technovation.2021.102255

Elahi, E., Weijun, C., Jha, S. K., and Zhang, H. (2019). Estimation of Realistic Renewable and Non-renewable Energy Use Targets for Livestock Production Systems Utilising an Artificial Neural Network Method: A Step towards Livestock Sustainability. Energy 183, 191-204. doi:10.1016/j.energy.2019.06.084 Friske, W., Nikolov, A. N., and Hoang, P. (2020). CSR Reporting Practices: an Integrative Model and Analysis. J. Marketing Theor. Pract. 28, 138-155. doi:10.1080/10696679.2019.1690397

Gudaro, A. M. (2012). Impact of Foreign Direct Investment on Economic Growth: a Case Study of Pakistan. Ibtjbs 8, 21-30. doi:10.46745/ilma.jbs.2012.08.02.03

Hao, W., Shah, S. M. A., Nawaz, A., Asad, A., Iqbal, S., Zahoor, H., et al. (2020). The Impact of Energy Cooperation and the Role of the One Belt and Road Initiative in Revolutionizing the Geopolitics of Energy Among Regional Economic Powers: An Analysis of Infrastructure Development and Project Management. Complexity 2020, 1-16. doi:10.1155/2020/8820021

Huo, C., Ahmed Dar, A., Nawaz, A., Hameed, J., albashar, G., Pan, B., et al. (202110129). Groundwater Contamination with the Threat of COVID-19: Insights into CSR Theory of Carroll's Pyramid. J. King Saud Univ. - Sci. 33, 101295. doi:10.1016/j.jksus.2020.101295

Huo, C., Hameed, J., Nawaz, A., Adnan Raheel Shah, S., albahser, G., Alqahtani, W., et al. (2021). Scientific Risk Performance Analysis and Development of Disaster Management Framework: A Case Study of Developing Asian Countries. J. King Saud Univ. - Sci. 33, 101348. doi:10.1016/j.jksus.2021.101348

Iqbal, N., Ahmad, N., Haider, Z., and Anwar, S. (2014). Impact of Foreign Direct Investment (FDI) on GDP: A Case Study from Pakistan. Ilshs 16, 73-80. doi:10.18052/www.scipress.com/ILSHS.16.73

Kabirifar, K., Mojtahedi, M., Wang, C., and Tam, V. W. Y. (2020). Construction and Demolition Waste Management Contributing Factors Coupled with Reduce, Reuse, and Recycle Strategies for Effective Waste Management: A Review. J. Clean. Prod. 263, 121265. doi:10.1016/j.jclepro.2020.121265

Khan, M. B., Huobao, X., and Saleem, H. (2019). Direct Impact of Inflow of Foreign Direct Investment on Poverty Reduction in Pakistan: a Bonds Testing Approach. Econ. Research-Ekonomska Istraživanja 32, 3647-3666. doi:10.1080/1331677X.2019.1670088

Khaver, A. A. (2019). Political Economy of Water Pollution in Pakistan: An Overview. Islamabad: Sustain. Dev. Policy Inst. 
Lu, W., Bao, Z., Lee, W. M. W., Chi, B., and Wang, J. (2021). An Analytical Framework of "Zero Waste Construction Site": Two Case Studies of Shenzhen, China. Waste Manage. 121, 343-353. doi:10.1016/j.wasman.2020.12.029

Lu, W., Chen, X., Peng, Y., and Shen, L. (2015). Benchmarking Construction Waste Management Performance Using Big Data. Resour. Conservation Recycling 105, 49-58. doi:10.1016/j.resconrec.2015.10.013

Maqsoom, A., Babar, Z., Shaheen, I., Abid, M., Kakar, M. R., Mandokhail, S. J., et al. (2021). Influence of Construction Risks on Cost Escalation of Highway-Related Projects: Exploring the Moderating Role of Social Sustainability Requirements. Iran J. Sci. Technol. Trans. Civ Engj. Sci. Technol. - Trans. Civ. Eng. 45, 2003-2015. doi:10.1007/s40996-021-00601-2

Mohammed, M., Shafiq, N., Abdallah, N. A. W., Ayoub, M., and Haruna, A. (2020). A Review on Achieving Sustainable Construction Waste Management through Application of 3R (Reduction, Reuse, Recycling): A Lifecycle Approach. IOP Conf. Ser. Earth Environ. Sci. 476, 012010. doi:10.1088/1755-1315/476/1/012010

Nawaz, A., Su, X., Din, Q. M. U., Khalid, M. I., Bilal, M., and Shah, S. A. R. (2020). Identification of the H\&S (Health and Safety Factors) Involved in Infrastructure Projects in Developing Countries-A Sequential Mixed Method Approach of OLMT-Project. Ijerph 17, 635. doi:10.3390/ijerph17020635

Nawaz, A., Su, X., and Nasir, I. M. (2021b). BIM Adoption and its Impact on Planning and Scheduling Influencing Mega Plan Projects-(CPEC-) Quantitative Approach. Complexity 2021, 1-9. doi:10.1155/2021/8818296

Nawaz, A., Waqar, A., Shah, S., Sajid, M., and Khalid, M. (2019). An Innovative Framework for Risk Management in Construction Projects in Developing Countries: Evidence from Pakistan. Risks 7, 24. doi:10.3390/risks7010024

Nour, A. I., Sharabati, A.-A. A., and Hammad, K. M. (2020). Corporate Governance and Corporate Social Responsibility Disclosure, 5, 20-41. doi:10.4018/IJSECSR.2020010102

Olanipekun, A. O., Omotayo, T., and Saka, N. (2021). Review of the Use of Corporate Social Responsibility (CSR) Tools. Sustainable Prod. Consumption 27, 425-435. doi:10.1016/j.spc.2020.11.012

Peng, B., Tu, Y., Elahi, E., and Wei, G. (2018). Extended Producer Responsibility and Corporate Performance: Effects of Environmental Regulation and Environmental Strategy. J. Environ. Manage. 218, 181-189. doi:10.1016/ j.jenvman.2018.04.068

Qin, Z., Ji, C., Su, X., and Nawaz, A. (2021). Probability Analysis of Construction Risk Based on Noisy-Or Gate Bayesian Networks. Reliab. Eng. Syst. Saf. 217, 107974. doi:10.1016/j.ress.2021.107974

Rivo-López, E., Villanueva-Villar, M., Michinel-Álvarez, M., and Reyes-Santías, F. (2021). Corporate Social Responsibility and Family Business in the Time of COVID-19: Changing Strategy? Sustainability 13, 2041-2113. doi:10.3390/su13042041
Tawfik Alqadami, A., Abdullah Zawawi, N. A. W., Rahmawati, Y., Alaloul, W., and Faisal Alshalif, A. (2020), Key Success Factors of Implementing Green Procurement in Public Construction Projects in Malaysia, IOP Conf. Ser.: Earth Environ. Sci., 498, 012098. doi:10.1088/1755-1315/498/1/012098

Tran, T. Q., Dang, T. A., Dang, T. A., and Tran, N. A. T. (2020). Factors Affecting Foreign Direct Investment: Evidence on Tay Ninh Province. Jafeb 7, 263-269. doi:10.13106/jafeb.2020.vol7.no9.263

Tu, Y., Peng, B., Wei, G., Elahi, E., and Yu, T. (2019). Regional Environmental Regulation Efficiency: Spatiotemporal Characteristics and Influencing Factors. Environ. Sci. Pollut. Res. 26, 37152-37161. doi:10.1007/s11356-019-06837-w

Wang, H., Tong, L., Takeuchi, R., and George, G. (2016). Corporate Social Responsibility: An Overview and New Research Directions. Amj 59, 534-544. doi:10.5465/amj.2016.5001

Wu, H., Zuo, J., Yuan, H., Zillante, G., and Wang, J. (2019). A Review of Performance Assessment Methods for Construction and Demolition Waste Management. Resour. Conservation Recycling 150, 104407. doi:10.1016/ j.resconrec.2019.104407

Zahoor, H., Khan, R. M., Nawaz, A., Ayaz, M., and Maqsoom, A. (2021a). Project Control and Forecast Assessment of Building Projects in Pakistan Using Earned Value Management. Ecam. ahead-of-print. doi:10.1108/ECAM-11-2020-0989

Zhou, S., Guo, Z., Ding, Y., Dong, J., Le, J., and Fu, J. (2021). Effect of Green Construction on a Building' S Carbon Emission and its Price at Materialization. Sustain 13, 1-15. 10.3390/su13020642

Conflict of Interest: The authors declare that the research was conducted in the absence of any commercial or financial relationships that could be construed as a potential conflict of interest.

Publisher's Note: All claims expressed in this article are solely those of the authors and do not necessarily represent those of their affiliated organizations, or those of the publisher, the editors, and the reviewers. Any product that may be evaluated in this article, or claim that may be made by its manufacturer, is not guaranteed or endorsed by the publisher.

Copyright (c) 2021 Avotra, Chenyun, Yongmin, Lijuan and Nawaz. This is an openaccess article distributed under the terms of the Creative Commons Attribution License (CC BY). The use, distribution or reproduction in other forums is permitted, provided the original author $(s)$ and the copyright owner(s) are credited and that the original publication in this journal is cited, in accordance with accepted academic practice. No use, distribution or reproduction is permitted which does not comply with these terms. 